\title{
Learning Organization Implementation Strategy for Developing Team Learning in Schools
}

\author{
Eva Miftahul Jannah* \\ Educational Administration Department, School of \\ Postgraduate Studies \\ Universitas Pendidikan Indonesia \\ Bandung, Indonesia \\ *evamj83@upi.edu
}

\author{
Cicih Sutarsih \\ Post Graduate School \\ Universitas Pendidikan Indonesia \\ Bandung, Indonesia
}

\begin{abstract}
In responding to any changes, ideas, creativity, and organizational resilience require learning in organization. Sensitive and responsive to stimuli from the outside environment give rise to learning organizations. The purpose of this study was to determine how the application of learning organizations in educational services in schools to develop learning teams that have implications for reliable teamwork in schools. The approach used in this research is a qualitative approach with observation and interviews. Data analysis was carried out by analytic descriptive, drawing conclusions or verification obtained through observation and interview notes. Schools need to implement a learning organization to develop the ability of teachers and employees to form team learning in schools. The results of the study are as follows: three important team learning behaviours, namely sharing, constructive conflict, and joint construction. The success of schools in developing team learning will create teachers and employees who can work more effectively in the future or produce innovative solutions to challenges that will be difficult to face. individually. Diversity of team expertise and good perception of assignments make a positive contribution to team learning development.
\end{abstract}

Keywords—learning organization, team learning, team work

\section{INTRODUCTION}

Senge argues that to build a learning organization can be done through five learning skills, namely: (1) thinking systemically; thinking thoroughly of all components of the school as a unit that influences each other, (2) personal mastery; learning skills to increase the personal capacity of school citizens in creating the most desired results and a school environment that encourages all school members to selfdevelop towards the goals and objectives selected, (3) mental models; skills that are continuously carried out through contemplation, clarification, and improvement of internal images of the school and seeing how it shapes the actions and decisions of school members in achieving the vision and mission of the school, (4) building a common vision; skills in building mutual commitment in a group of teachers, and (5) team learning; skills to change abilities in a dialogue and collective thinking, so that groups of teachers can develop intelligence and are greater than the number of talents and abilities of individual teachers [1].

Kozlowski and Bell explained that this Learning Organization is needed in the era of globalization because the world of education is facing global challenges and changes. This creates pressure for the organization so that it affects the emergence of teams within the organization as the organization's shield in facing these challenges and competitions [2].

Learning organizations also provide a variety of learning program opportunities for individual and collective development. Learning and development programs are in place to ensure that individuals and teams develop competences for reflective practice and collaborative learning. Arnold Toynebe also added that leaders must fully realize the importance of providing motivation, means, and learning opportunities to team members. Leaders take an exemplary leadership role in creating and maintaining a supportive learning culture [3].

In this study we want to explore the implementation strategy of learning organization in developing team learning. The reason for choosing this study is because team learning is an important part of collaborating on teacher learner ideas as well as forming an organizational culture in creating innovative practices in schools.

The purpose of this study was to determine how the strategy for implementing learning organizations in developing team learning in a private elementary school in Bandung. This private elementary school became the author's research site because in the 5 years since the school's establishment, the school has experienced rapid progress. This can be seen from the school's programs that are always creative and innovative or adapt to trends in education. We think that the school not only has adequate facilities, but also has a reliable team of teachers. The teacher team was formed on the basis of diverse teacher knowledge and different experiences and was also supported by the high efficacy of the teachers in the school.

Previous research, such as the narrative of Argote, stated that a group of highly skilled individuals did not fully produce 
a team with good team learning. A good team is a team with varying degrees of diversity in the context of the knowledge abilities of team members. This means that the ability of a diverse team will have various points of view so that it has the potential to create a creative thinking process. In addition, as stated by Van der Vegt and Bunderson, the diversity of skills of team members is useful for team performance. Diverse and different knowledge, skills and abilities can enhance the learning process [4].

As argued by Edmonson There are other factors that determine the success of team learning besides the cognitive abilities of team members, another aspect that is taken into consideration is the strong belief that team members have that the team can complete tasks and solve problems. This is what is called team efficacy.

The results of the above research will be used as study material for our research where this study wants to explore how the implementation strategy of learning organization implemented in private schools where this research is conducted can develop team learning. Our hypothesis is that team learning will be formed because of the learning process within the scope of individuals, groups and organizations carried out by team members as teacher learners. Is it possible if team learning in the school arises from the diversity of knowledge and efficacy of team members.

\section{RESEARCH METHODS}

The approach used in this research is qualitative research. The data analysis used is descriptive analytic conclusion or verification obtained through observation and interview notes. The research instrument used interview and observation guidelines in the form of google form which consists of 30 questions. The question items consisted of aspects of learning skills as well as aspects of team learning. Participants who were taken as research samples were 22 people consisting of 16 women and 6 men. Samples were taken randomly and basically have almost the same characteristics as the characteristics of participants who have different cognitive abilities and experiences, different educational backgrounds, and gender. The place of research taken is a private elementary school in Bandung.

\section{DISCUSSION}

Arnold Toynebe stated that learning organizations provide various kinds of learning program opportunities for individuals and collective development. Learning and development programs are in place to ensure that individuals and teams develop competences for reflective practice and collaborative learning. added also that the leader must fully realize the importance of providing motives, means, and learning opportunities to team members. Leaders take an exemplary leadership role in creating and maintaining a supportive learning culture. Therefore, this study aims to explore learning programs, tools, and leadership roles that underlie learning organizations related to team learning development.
Based on the aspects of skills developed in organizations as described in the five disciplines defined by Senge in the aspect of team learning, the results obtained are:

The results of observations of 22 participants can be seen that $94 \%$ of team members admit that the school is very concerned about the facilities needed by teachers to improve skills according to their respective fields, the leadership of the principal in instilling a vision, school values to team members, strong motivation and commitment, and the principal's courage in taking risks in responding to any changes. Likewise, the principal always makes school programs that can support the development of teacher skills, high motivation from teachers in participating in the quality of learning upgrading program. This means that schools have in such a way prepared efforts to implement strategies for implementing learning organizations in schools. such as the results of interviews with private elementary school curriculum in Bandung that the principal is doing weekly evaluations to see the results of the achievements made by team members from the results of the training held every weekend.

The training program is carried out for teachers according to what skills are the target teachers. Several training programs such as tahsin training, leadership training, literacy training, digital training, curriculum training, and academic training. Some of these skills training has contributed to increasing the insight of teachers or team members in all divisions. Not only up to gaining knowledge or expertise, team members are required to be able to share knowledge and use this knowledge for school progress. According to McShane and Glinow, learning activities consist of three organizational aspects, namely (1) knowledge acquisition, (2) knowledge sharing, and (3) knowledge use. This organizational aspect can also be realized in the development of team learning in schools.

Decuyper et al identified three important team learning behaviours, namely sharing, constructive conflict, and joint construction. Sharing is defined as "the process of communicating knowledge, competencies, quotes, opinions, or creative thoughts from one team member to another, which were not previously aware that this is on the team. Constructive conflict is seen as "a complicated conflict or discussion that stems from diversity and open communication, and leads to further communication and a kind of temporary agreement, joint construction refers to the process of developing shared knowledge. Lee and Pavola add that the three team learning behaviours are considered relevant for develop innovative solutions collectively: share available cognitive resources and unique expertise, integrate different viewpoints, and collaboratively build new knowledge [5].

From the results of observations obtained regarding team learning, it is directly proportional to the efforts to implement a learning organization strategy in schools, such as the following data: $80 \%$ stated that teachers always conduct peer teaching with peers to gain insight, $87 \%$ of teachers state that communication between team members is running well, $98 \%$ of the participation of members in the team is increasing, $98 \%$ 
of teachers are always open to expressing opinions or conveying ideas, and $99 \%$ of participants say they always think about the team's interests for school progress, have the ability to work with other people between departments, and teachers can understand the he goals team in fighting the school program goals. The results of this study mean that the potential of team members in learning has been formed. The results of the interviews with participants indicated that the team members in the private school understood the task very well. The perception of the task is given a positive meaning as a form of responsibility and their contribution to team learning. They try to complete assignments properly and perfectly so that school goals can be achieved.

Even this team learning is supported by the diversity of educational backgrounds of the team members, such as $68 \%$ undergraduate and 32\% high school graduates. Diverse educational backgrounds consisting of bachelors in engineering, diniyyah, and exacts have contributed significantly to the emergence of creative ideas for solving problems within the team. The diversity of expertise and experience in the team will encourage team members to exchange information and complement incomplete information and knowledge so that they have a more complete perspective in solving problems. Furthermore, the belief that the team can carry out difficult and challenging tasks is also important, so that the team ventures out to experiment and do learning. Earley and Masakowski stated that the availability of various resources and skills in a team with a high diversity of members will cause this team to be more innovative and creative in problem solving compared to a team whose members tend to be homogeneous.

\section{CONCLUSION}

The process of developing science, the skills of teachers according to their expertise will support the performance of an increasingly reliable team to achieve the vision, mission and goals expected by a school. Efforts made by schools to improve teacher skills can be carried out with various training programs. Training that can be done is in the form of academic, management, and technology application skills training. This training is useful in exploring the potential for more than team members to share knowledge and use knowledge in solving team problems. Likewise, the leadership process of the principal has a big role in implementing a learning organization implementation strategy in schools. The formation of team learning will encourage teachers to work on innovative collaborative assignments that will play an important role in achieving educational change.

Further research can be carried out in the context of team learning by paying attention to the distribution of participants with the criteria of working age and age, so that it can be seen that team learning is in accordance with these criteria. And there is no known research on team learning with inspirational leadership in certain schools.

\section{REFERENCES}

[1] G. Wiyono, "Strategi Penerapan Organizational Learning untuk Membentuk Guru Pembelajar di Sekolah,” Jurnal Edukasi Elektro, vol. 1 , no. 1 , pp. 69-77, 2017.

[2] N.D. Shortland, L.J. Alison and J.M. Moran, Team Learning. In Conflict (pp. 120-137). Oxford University Press, 2019.

[3] P. Van den Bossche, W. Gijselaers, M. Segers, G. Woltjer and P. Kirschner, "Team learning: building shared mental models," Instructional Science, vol. 39, no. 3, pp. 283-301, 2011.

[4] V.G.R. Pohan and D. Ancok, "Team Learning Ditinjau dari Team Diversity dan Team Efficacy," Jurnal Psikologi, vol. 37, nol. 2, pp. 203215, 2015.

[5] M.G. Koeslag-Kreunen, M.R. Van der Klink, P. Van den Bossche and W.H. Gijselaers, "Leadership for team learning: The case of university teacher teams," Higher Education, vol. 75, no. 2, pp. 191-207, 2018. 